\title{
Detection of high cardiovascular risk patients with ankylosing spondylitis based on the assessment of abdominal aortic calcium as compared to carotid ultrasound
}

Javier Rueda-Gotor ${ }^{1 *}$ (D), Fernanda Genre ${ }^{1 \dagger}$, Alfonso Corrales ${ }^{1}$, Ricardo Blanco ${ }^{1}$, Patricia Fuentevilla', Virginia Portilla ${ }^{1}$, Rosa Expósito², Cristina Mata², Trinitario Pina', Carlos González-Juanatey³, Luis Rodriguez-Rodriguez ${ }^{4 \dagger}$

and Miguel A. González-Gay ${ }^{1,5+}$

\begin{abstract}
Background: This study aimed to determine whether, besides carotid ultrasound (US), a lateral lumbar spine radiography may also help identify ankylosing spondylitis (AS) patients at high risk of cardiovascular (CV) disease.

Methods: A set of 125 AS patients older than 35 years without a history of CV events, diabetes mellitus, or chronic kidney disease was recruited. Carotid US and lateral lumbar spine radiography were performed in all of them. The CV risk was calculated according to the total cholesterol systematic coronary risk evaluation (TC-SCORE) algorithm. Presence of carotid plaques was defined following the Mannheim Carotid Intima-media Thickness and Plaque Consensus. Abdominal aortic calcium (AAC) in a plain radiography was defined as calcific densities visible in an area parallel and anterior to the lumbar spine.
\end{abstract}

Results: Carotid US showed higher sensitivity than lateral lumbar spine radiography to detect high CV risk in the 54 patients with moderate TC-SCORE (61\% versus 38.9\%). Using carotid plaques as the gold standard test, a predictive model that included a TC-SCORE $\geq 5 \%$ or the presence of AAC in the lateral lumbar spine radiography in patients with both moderate and low CV risk ( $<5 \%$ ) according to the TC-SCORE yielded a sensitivity of $50.9 \%$ with a specificity of $95.7 \%$ to identify high/very high CV-risk AS patients. A positive correlation between AAC and carotid plaques was observed $\left(r^{2}=0.49, p<0.001\right)$.

Conclusions: A lateral lumbar spine radiography is a useful tool to identify patients with AS at high risk of CV disease.

Keywords: Ankylosing spondylitis, Cardiovascular disease, Abdominal aortic calcification, Lumbar lateral spine radiography, Carotid ultrasonography

\section{Background}

As occurs with other chronic inflammatory conditions, ankylosing spondylitis (AS) is associated with a process of accelerated atherosclerosis $[1,2]$ which leads to increased rates of subclinical atherosclerosis [3] and cardiovascular (CV) events

\footnotetext{
* Correspondence: ruedagotor@gmail.com

†'Miguel A. González-Gay, Fernanda Genre and Luis Rodriguez-Rodriguez are contributed equally to this work.

${ }^{1}$ Epidemiology, Genetics and Atherosclerosis Research Group on Systemic Inflammatory Diseases, Division of Rheumatology, Hospital Universitario Marqués de Valdecilla, IDIVAL, University of Cantabria, Avenida de Valdecilla, $s / n, 39008$ Santander, Spain

Full list of author information is available at the end of the article
}

[4]. A recent meta-analysis of seven longitudinal studies reported an increased frequency of myocardial infarction (odds ratio $(\mathrm{OR}) 1.60$, 95\% confidence interval $(\mathrm{CI}) 1.32-1.93)$ and stroke (OR 1.50, 95\% CI 1.39-1.62) in AS patients when compared to the general population [4]. In a population-based study which included 21,473 AS patients and 86,606 controls matched for age, sex, and location of residence, Haroon et al. [5] found a 36\% higher risk of vascular mortality in AS.

Primary prevention strategies designed to avoid atherosclerosis-related $\mathrm{CV}$ events in the general population are based on the identification of individuals at high

(C) The Author(s). 2018 Open Access This article is distributed under the terms of the Creative Commons Attribution 4.0 International License (http://creativecommons.org/licenses/by/4.0/), which permits unrestricted use, distribution, and 
$\mathrm{CV}$ risk who can benefit from appropriate prevention measures [6]. In this regard, statin use has proved to be very effective, being able to reduce overall mortality by $15 \%$ [7]. The benefit may be even greater in AS patients according to a recent study which found a 37\% lower risk of all-cause mortality associated with statin initiation [8].

The 2016 "European Guidelines on CV disease prevention in clinical practice" recommended using the total cholesterol systematic coronary risk evaluation (TC-SCORE) to stratify the CV risk and to identify individuals at high $\mathrm{CV}$ risk who were candidates for treatment [6]. The TC-SCORE predicts the individual's absolute risk for fatal $\mathrm{CV}$ events considering age, sex, total cholesterol levels, smoking, and blood pressure, stratifying the CV risk into low $(<1 \%)$, moderate $(\geq 1$ and $<5 \%$ ), high ( $\geq 5$ and $<10 \%$ ), and very high $(\geq 10 \%)$.

Unfortunately, predictive models designed for the general population do not consider the inflammatory process as a proatherogenic factor, leading to an underestimation of the $\mathrm{CV}$ risk when used in inflammatory diseases like AS. In this regard, a recent study disclosed in AS patients a 10-year cumulative incidence of CV events three times higher than that predicted based on the Framingham Risk Score (FRS) [9].

In an attempt to improve the TC-SCORE predictions, the 2016 European Society of Cardiology (ESC) guidelines proposed the use of different imaging techniques to identify high-CV risk individuals with subclinical atherosclerosis [6]. Carotid ultrasonography (US) and multidetector coronary tomography (MDCT) allow one to detect, respectively, carotid plaques and coronary calcifications, which are considered independent predictors of $\mathrm{CV}$ events capable of providing additional value to the FRS when estimating CV risk [10, 11]. According to the 2016 ESC guidelines, the presence of both surrogate markers of atherosclerosis automatically implies a very high CV risk [6]. Our group has recently demonstrated that carotid US and MDCT are very useful to redefine the CV risk in AS: up to $63 \%$ and $30 \%$ of our AS patients with moderate CV risk according to the SCORE risk charts had carotid plaques and coronary calcifications, respectively [12]. However, the restricted availability of MDCT in the daily clinical practice and the considerable amount of radiation associated with the use of this technique may be limitations for to its generalized use.

Abdominal aortic calcium (AAC) constitutes another surrogate marker of atherosclerosis easily detectable in a lateral lumbar spine radiography [13]. Unlike MDTC, it is available in most AS patients. Aortic calcification has been demonstrated to represent true intimal atherosclerosis in postmortem studies [14], correlating with the degree of atherosclerosis in the coronary arterial beds [15]. As occurs with carotid plaques and coronary calcification, AAC deposits constitute an independent predictor of subsequent vascular morbidity and mortality capable of improving the risk prediction based on the FRS [16].

Taking all these considerations into account, the purpose of the present study is to determine whether, besides carotid US, the presence of ACC deposits detected by plain lumbar spine radiographs is able to improve the identification of those AS patients with high/very high $\mathrm{CV}$ risk who, therefore, would be candidates to receive intensive preventive therapy.

\section{Methods \\ Patients}

In this cross-sectional study, a set of 125 consecutive AS patients seen over a 5-year period at Hospital Universitario Marqués de Valdecilla and Hospital de Laredo (Cantabria, northern Spain) who fulfilled definitions for AS according to the 1984 modified New York criteria [17] were recruited. Patients with a history of CV events (ischemic heart disease, cerebrovascular accident, peripheral arterial disease, or heart failure) were excluded. This was also the case for those with type 2 diabetes mellitus or with two fasting plasma glucose levels on different days at the time of disease diagnosis or over the extended follow-up $>125 \mathrm{mg} / \mathrm{dl}$ as well as those with chronic kidney disease (glomerular filtration rate $<60 \mathrm{ml} / \mathrm{min} /$ $1.73 \mathrm{~m}^{2}$ ) because they are considered as having high or very high $\mathrm{CV}$ risk according to current guidelines.

Two clinical indexes of disease activity (Bath Ankylosing Spondylitis Disease Activity Index (BASDAI) and Ankylosing Spondylitis Disease Activity Score (ASDAS)), a functional status index (Bath Ankylosing Spondylitis Functional Index (BASFI)), a metrologic index (Bath Ankylosing Spondylitis Metrology Index (BASMI)), and an enthesitis index (Maastricht Ankylosing Spondylitis Enthesitis Score (MASES)) were evaluated in all patients at the time of the carotid US assessment [18-22].

Information on history of hip involvement, synovitis, enthesitis, extra-articular manifestations (anterior uveitis, psoriasis, and inflammatory bowel disease), syndesmophytes, and HLA-B27 status was also assessed. This was also the case for data on family history of early $\mathrm{CV}$ events in first-degree relatives, waist circumference, body mass index, blood pressure at the time of study, and history of traditional CV risk factors (smoking, hypertension, dyslipidemia, and obesity).

Data on C-reactive protein (CRP) and the erythrocyte sedimentation rate (ESR) at the time of recruitment and at disease diagnosis, identification of patients with CRP serum levels higher than $3 \mathrm{mg} / \mathrm{L}$ at the time of diagnosis, and total cholesterol, HDL-cholesterol, LDL-cholesterol, and triglycerides at the time of the study were also assessed. Information on therapy including treatment 
with anti-tumor necrosis factor (anti-TNF) alpha agents from the disease diagnosis was also reviewed.

The TC-SCORE system estimates the 10-year risk of a first fatal atherosclerotic event, whether heart attack, stroke, or other occlusive arterial disease, including sudden cardiac death. Risk estimates have been produced as charts for high and low-risk regions in Europe [6]. Spain was included in the low-risk region of Europe. The risk factors incorporated in the TC-SCORE are those previously described: age, gender, smoking, total cholesterol levels, and systolic blood pressure. Subjects with TC-SCORE $<1 \%$ are included in the category of low risk. Those with a TC-SCORE $\geq 1 \%$ and $<5 \%$ are in the category of moderate risk. When the chart TC-SCORE result is $\geq 5 \%$ and $<10 \%$ they are classified as having high risk. Finally, those patients with TC-SCORE results $\geq$ $10 \%$ are included in the category of very high CV risk.

The earliest age at which the CV risk scores should be used in the general population has not been rigorously established. Both European [6] and North American [23] guidelines recommend their application in individuals over 40 years old. However, this cutoff point is not uniform and varies across the different $\mathrm{CV}$ risk scores: 30 years old for the FRS [24], 40 years old for the TC-SCORE [6], and 45 years old for the Reynolds Risk Score [25], which can only be applied from this age onward. In Spain, the Framingham-based REGICOR adapted function, a CV risk function validated in the Spanish population [26], established its use at an intermediate point of 35 years old. Since patients with AS have early accelerated atherosclerosis, and we observed carotid plaques in patients under 40 years old, we included in the analysis all patients who were age 35 years and older.

\section{Carotid US examination}

A set of 125 AS patients underwent carotid US examination to detect focal plaques in the extracranial carotid tree. According to the Mannheim Carotid Intima-media Thickness and Plaque Consensus, a carotid plaque was defined as a focal protrusion in the lumen at least cIMT $>1.5 \mathrm{~mm}$, protrusion at least $50 \%$ greater than the surrounding cIMT, or arterial lumen encroaching $>0.5 \mathrm{~mm}$ [27]. Carotid US was performed using a commercially available scanner (Mylab 70; Esaote, Genoa, Italy) equipped with a 7-12 $\mathrm{MHz}$ linear transducer and the automated software-guided radiofrequency technique Quality Intima Media Thickness in real time (QIMT; Esaote, Maastricht, Holland). Patients with carotid plaques were considered as having very high CV risk.

\section{Evaluation of abdominal aortic calcium deposits}

The lateral lumbar spine radiography was performed in the standing position and all X-ray scans were evaluated by an independent reader blinded to the participant's clinical status. We assessed the presence of calcific deposits at each vertebral segment from the first to fourth lumbar vertebrae, both in the posterior and anterior walls of the aorta (Fig. 1). Calcific deposits were regarded as present if densities were visible in an area parallel to the lumbar spine and anterior to the lower part of the spine. Aortic densities at the upper part of the lumbar spine (L1-L2 region) often overlapped the vertebrae as the abdominal aorta in the L1-L2 region is often lateral to the spine. Densities overlapping the vertebrae were deemed present only if they extended from or formed a clear pattern with those of the lower part of the aorta. Since calcific deposits tend to occur first in the lower aorta [28, 29], calcific deposits at the upper levels were almost always accompanied by extensive calcifications in the lower part of the aorta. Other calcific deposits visible in lumbar films, such as intestinal calcifications and calcified costal cartilages, were clearly distinguishable from aortic calcifications (Fig. 1).

The reproducibility of the evaluation of AAC deposits was also evaluated in 20 patients by two investigators (JR-G and $\mathrm{AC}$ ). The correlation coefficient for AAC was 0.96 .

The subject's written consent was obtained for all of the cases. The study was approved by the local ethical committee.

\section{Statistical analysis}

Categorical variables were described as percentages and quantitative variables as mean \pm standard deviation (SD) or median (interquartile range (IQR)).

Correlation between the presence of carotid plaques and lumbar aortic calcification was analyzed using the Pearson correlation. For each CV risk model, sensitivity, specificity, percentage of correctly classified patients, and area under the receiver operating characteristic (ROC) curve (with 95\% CI) were estimated.

\section{Results}

\section{Characteristics of AS patients}

The main features of the 125 AS patients included in the study are summarized in Table 1 .

Men outnumbered women $(n=78 ; 62.4 \%)$ and the mean $\pm S D$ age at the time of the study was $48.3 \pm$ 9.6 years. HLA-B27 was positive in $92(74.8 \%)$ patients, and syndesmophytes were present in $51(41.5 \%)$ patients. Thirty-eight $(30.4 \%)$ patients had extra-articular manifestations: uveitis, psoriasis, and inflammatory bowel disease were present in $17.6 \%, 9.6 \%$, and $8 \%$ of patients, respectively. The mean \pm SD values of the BASDAI and ASDAS were $3.7 \pm 2.0$ and $2.4 \pm 0.9$. Seventy-two (57.6\%) patients were found to have CRP $>3 \mathrm{mg} / \mathrm{L}$ at the time of disease diagnosis. TNF inhibitors were used in $39.8 \%$ of cases. Regarding findings of subclinical atherosclerosis, 


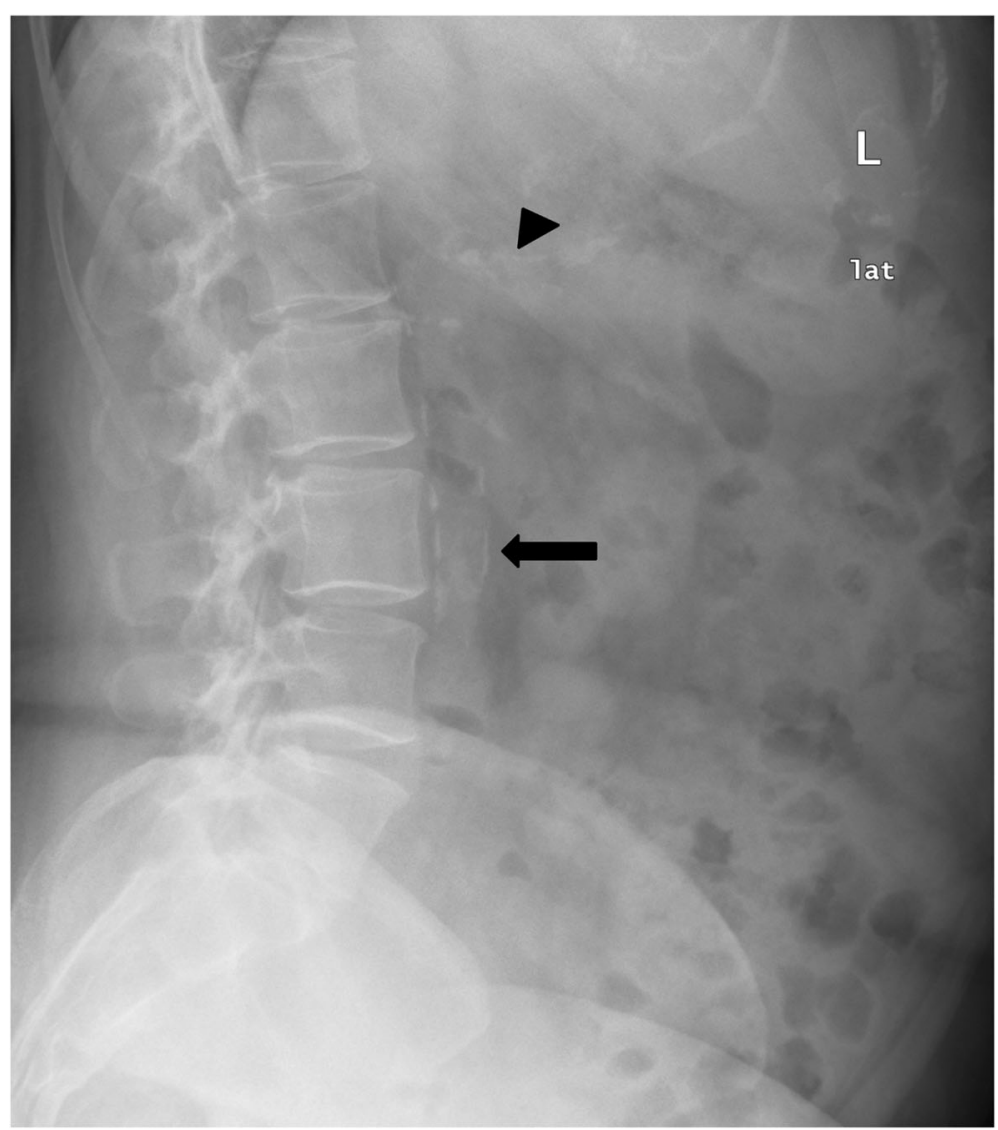

Fig. 1 Abdominal aortic calcifications and calcified costal cartilages. Abdominal aortic calcifications seen as calcium deposits localized in area parallel to lumbar spine and anterior to lower part of spine (long arrow). Calcified costal cartilages have a typical pattern distinguishable from aortic calcifications (arrowhead)

carotid plaques and AAC deposits were found in 55 $(44.0 \%)$ and $28(22.4 \%)$ patients, respectively. Other characteristics of this series of patients with AS are presented in Table 1.

\section{TC-SCORE risk groups and severe atherosclerotic disease using carotid US and lateral spine radiography}

The CV risk was calculated using the TC-SCORE. Based on this algorithm, patients were classified into four different CV risk categories: low, moderate, high, and very high. Then, the frequency of carotid plaques in each category was calculated to assess the ability of the TC-SCORE to correctly classify patients as having high/ very high $\mathrm{CV}$ risk (Table 2). We also analyzed the prevalence of AAC in the lateral spine radiography in each group of risk (Table 2). Following this approach, 33 of 54 (61.1\%) patients classified as having moderate CV according to the TC-SCORE had plaques when the carotid US was performed, whereas 21 of 54 (38.9\%) patients with moderate $\mathrm{CV}$ risk according to the TC-SCORE also had AAC in the lateral lumbar spine radiography. Moreover, $23.4 \%$ and $4.7 \%$ of AS patients who fulfilled the category of low $\mathrm{CV}$ risk according to the TC-SCORE had carotid plaques and AAC, respectively (Table 2).

\section{Correlation between AAC and carotid US in AS patients}

The validity of lateral lumbar spine radiography to identify AS patients at high CV risk was assessed by analyzing the correlation between AAC and carotid plaques (Table 3). We observed that 25 of 28 (89.3\%) patients with AAC deposits also had plaques in the carotid US assessment. Regarding patients without AAC deposits in the lateral lumbar spine radiography, $69.1 \%$ of them did not have carotid plaques either (Table 3). We observed a positive correlation between AAC and carotid plaques $\left(r^{2}=0.49, p<0.001\right)$.

\section{Model to establish the presence of high/very high CV risk in patients with AS}

Since many patients categorized as having low or moderate $\mathrm{CV}$ risk when the TC-SCORE was applied had subclinical atherosclerosis, we set up a predictive model to identify AS patients with high/very high CV risk (Table 4). In this regard, according to the ESC 2016 guidelines, we 
Table 1 Features of 125 ankylosing spondylitis (AS) patients

\begin{tabular}{|c|c|}
\hline Variable & $\mathrm{AS}(n=125)$ \\
\hline Men/women, $n$ & $78 / 47$ \\
\hline Age at time of study (years), mean $\pm S D$ & $48.3 \pm 9.6$ \\
\hline Age at time of diagnosis (years), mean $\pm S D$ & $39.5 \pm 9.6$ \\
\hline HLA-B27 positive, $n(\%)$ & $92(74.8)$ \\
\hline Syndesmophytes, $n$ (\%) & $51(41.5)$ \\
\hline History of synovitis, $n(\%)$ & $35(28.0)$ \\
\hline History of enthesitis, $n(\%)$ & $45(36.0)$ \\
\hline Extra-articular manifestations, $n$ (\%) & $38(30.4)$ \\
\hline Psoriasis & $12(9.6)$ \\
\hline Inflammatory bowel disease & $10(8.0)$ \\
\hline Uveitis & $22(17.6)$ \\
\hline Therapy with TNF inhibitors, $n$ (\%) & $49(39.8)$ \\
\hline ASDAS, mean \pm SD & $2.4 \pm 0.9$ \\
\hline $\mathrm{BASFl}$, mean $\pm \mathrm{SD}$ & $3.9 \pm 2.5$ \\
\hline $\mathrm{BASMI}$, mean $\pm \mathrm{SD}$ & $3.2 \pm 1.7$ \\
\hline MASES, median (IQR) & $1(0.0-4.0)$ \\
\hline $\mathrm{BASDAl}$, mean $\pm \mathrm{SD}$ & $3.7 \pm 2.0$ \\
\hline \multicolumn{2}{|l|}{ CRP (mg/l), median (IQR) } \\
\hline At time of study & $5.2 \pm 6.7$ \\
\hline At time of disease diagnosis & $10.8 \pm 19.0$ \\
\hline CRP $>3 \mathrm{mg} / \mathrm{L}$ at time of disease diagnosis, $n(\%)$ & $72(57.6)$ \\
\hline \multicolumn{2}{|l|}{ ESR (mm/1st hour), median (IQR) } \\
\hline At time of study & $12.4 \pm 13.4$ \\
\hline At time of disease diagnosis & $16.1 \pm 15.9$ \\
\hline \multicolumn{2}{|l|}{ History of classic cardiovascular risk factors, $n(\%)$} \\
\hline Current smokers & $37(29.6)$ \\
\hline Ex-smokers & $31(24.8)$ \\
\hline Obesity & $23(18.4)$ \\
\hline Dyslipidemia & $40(32.0)$ \\
\hline Hypertension & $21(16.8)$ \\
\hline \multicolumn{2}{|l|}{ Blood pressure $(\mathrm{mmHg})$, mean $\pm \mathrm{SD}$} \\
\hline Systolic & $130.6 \pm 15.3$ \\
\hline Diastolic & $79.5 \pm 9.7$ \\
\hline \multicolumn{2}{|l|}{ Cholesterol and triglycerides $(\mathrm{mg} / \mathrm{dl})$, mean $\pm \mathrm{SD}$} \\
\hline Total cholesterol & $200.7 \pm 34.5$ \\
\hline HDL cholesterol & $55.6 \pm 14.8$ \\
\hline LDL cholesterol & $124.6 \pm 31.7$ \\
\hline Triglycerides & $97.3 \pm 49.4$ \\
\hline Carotid plaques, $n(\%)$ & $55(44.0)$ \\
\hline Aortic calcification, $n(\%)$ & $28(22.4)$ \\
\hline TC-SCORE $\geq 5, n(\%)$ & $7(5.6)$ \\
\hline
\end{tabular}

Main epidemiologic, clinical, radiographic, and ultrasonography features of a series of 125 AS patients older than 35 years of age without history of cardiovascular events, diabetes mellitus, or chronic kidney disease ASDAS Ankylosing Spondylitis Disease Activity Score, BASDAI Bath Ankylosing Spondylitis Disease Activity Index, BASFI Bath Ankylosing Spondylitis Functional Index, BASMI Bath Ankylosing Spondylitis Metrology Index, CRP C-reactive protein, ESR erythrocyte sedimentation rate, $H D L$ high-density lipoprotein, IQR interquartile range, LDL low-density lipoprotein, MASES Maastricht Ankylosing Spondylitis Enthesitis Score, SD standard deviation TC-SCORE total cholesterol systematic coronary risk evaluation, $T N F$ tumor necrosis factor
Table 2 Prevalence of carotid plaques and abdominal aortic calcium in the different groups of cardiovascular risk

\begin{tabular}{llll}
\hline TC-SCORE & & $\begin{array}{l}\text { Carotid ultrasonography } \\
\text { Carotid plaques } \\
(n=55,44 \%)\end{array}$ & $\begin{array}{l}\text { Lateral lumbar X-ray } \\
\text { AAC deposits } \\
(n=28,22.4 \%)\end{array}$ \\
\hline $\begin{array}{l}\text { Low }(<1 \%) \\
\begin{array}{l}\text { Moderate } \\
(\geq 1 \% \text { and }<5 \%)\end{array}\end{array}$ & $n=64$ & $15 / 64(23.4 \%)$ & $3 / 64(4.7 \%)$ \\
$\begin{array}{l}\text { High }(\geq 5 \% \text { and } \\
<10 \%)\end{array}$ & $n=7$ & $7 / 7(100 \%)$ & $21 / 54(38.9 \%)$ \\
Very high $(\geq 10 \%)$ & $n=0$ & $0(0 \%)$ & $4 / 7(57.1 \%)$ \\
\hline
\end{tabular}

Presence of carotid plaques and AAC deposits in 125 ankylosing spondylitis patients older than 35 years of age without cardiovascular events, diabetes mellitus, or chronic kidney disease, classified according to their cardiovascular risk

AAC abdominal aortic calcium, TC-SCORE total cholesterol systematic coronary risk evaluation

classified patients as having high/very high CV risk if they had carotid plaques in the carotid US [6]. Following this approach, 55 of 125 patients fulfilled definitions of high/ very high CV risk. However, only 7 (12.7\%) of them were detected using the TC-SCORE, without the inclusion in the model of results of imaging techniques (model 1). The detection of aortic atherosclerosis by lateral lumbar spine radiography yielded a high specificity (95.7\%) with low sensitivity (45.5\%) to identify AS patients with very high $\mathrm{CV}$ risk (model 2). A predictive model that included a TC-SCORE $\geq 5 \%$ or the presence of AAC in lateral lumbar spine radiography in patients with moderate $\mathrm{CV}$ risk according to the SCORE $(\geq 1 \%$ and $<5 \%$ ) (model 3 ) showed the same results as those found in model 2. A higher sensitivity (50.9\%) with the same specificity (95.7\%) was achieved when the predictive model included TCSCORE $\geq 5 \%$ or the presence of AAC in the lateral lumbar spine radiography in patients with both moderate and low CV risk according to the TC-SCORE (<5\%) (model 4).

\section{Discussion}

To the best of our knowledge this is the first study that aimed to assess the ability of the lateral lumbar spine radiography, a diagnostic tool widely available in AS

Table 3 Correlation between abdominal aortic calcium (AAC) deposits and carotid plaques

\begin{tabular}{llll}
\hline Lateral lumbar X-ray & \multicolumn{2}{l}{ Carotid ultrasonography } \\
\cline { 3 - 4 } & $\begin{array}{l}\text { Presence of carotid } \\
\text { plaques } \\
(n=55 / 125,44 \%)\end{array}$ & $\begin{array}{l}\text { Absence of carotid } \\
\text { plaques } \\
(n=70 / 125,56 \%)\end{array}$ \\
\hline $\begin{array}{l}\text { Presence of } \\
\text { AAC }\end{array}$ & $\begin{array}{l}n=28 \\
(22.4 \%)\end{array}$ & $3 / 28(10.7)$ \\
Absence of & $\begin{array}{l}n=97 \\
\text { AAC }\end{array}$ & $30 / 97(30.9 \%)$ & $67 / 97(69.1 \%)$ \\
\hline
\end{tabular}

Correlation between the presence of AAC deposits and the presence of carotid plaques in 125 patients with ankylosing spondylitis older than 35 years of age without cardiovascular events, chronic kidney disease, or diabetes mellitus 
Table 4 Diagnostic models designed to identify ankylosing spondylitis patients with very high cardiovascular risk using presence of carotid plaques as the gold standard test

\begin{tabular}{|c|c|c|c|c|}
\hline & $\begin{array}{l}\text { Sensitivity } \\
(\%)\end{array}$ & $\begin{array}{l}\text { Specificity } \\
(\%)\end{array}$ & $\begin{array}{l}\text { Correctly } \\
\text { classified } \\
(\%)\end{array}$ & $\begin{array}{l}\text { ROC } \\
(95 \% \mathrm{Cl})\end{array}$ \\
\hline $\begin{array}{l}\text { Model } 1 . \\
\text { TC-SCORE } \geq 5 \%\end{array}$ & 12.7 & 100 & 61.6 & $\begin{array}{l}0.56 \\
(0.52-0.61)\end{array}$ \\
\hline $\begin{array}{l}\text { Model 2. Lateral } \\
\text { lumbar spine } \\
\text { radiography } \\
\text { (presence of AAC) }\end{array}$ & 45.5 & 95.7 & 73.6 & $\begin{array}{l}0.71 \\
(0.64-0.78)\end{array}$ \\
\hline $\begin{array}{l}\text { Model 3. TC-SCORE } \geq \\
5 \% \text { or TC-SCORE } \geq 1 \% \\
\text { and }<5 \% \text { plus lateral } \\
\text { lumbar spine radiography } \\
\text { (presence of AAC) }\end{array}$ & 45.5 & 95.7 & 73.6 & $\begin{array}{l}0.71 \\
(0.64-0.78)\end{array}$ \\
\hline $\begin{array}{l}\text { Model 4. TC-SCORE } \geq 5 \% \\
\text { or TC-SCORE }<5 \% \text { plus } \\
\text { lateral lumbar spine } \\
\text { radiography } \\
\text { (presence of AAC) }\end{array}$ & 50.9 & 95.7 & 76.0 & $\begin{array}{l}0.73 \\
(0.66-0.80)\end{array}$ \\
\hline
\end{tabular}

$A A C$ abdominal aortic calcium, $\mathrm{Cl}$ confidence interval, $R O C$ receiver operating characteristic, TC-SCORE total cholesterol systematic coronary risk evaluation

patients, to improve the $\mathrm{CV}$ risk stratification in patients with AS. We observed that the presence of AAC deposits detected by a lateral lumbar spine radiography allows one to identify individuals with AS at high risk of $\mathrm{CV}$ disease. In this regard, in the present series of 125 AS patients without CV events, chronic kidney disease, or diabetes mellitus, 21 of 54 (38.9\%) patients with moderate TC-SCORE and 3 of 64 (4.7\%) patients with low TC-SCORE showed AAC in the lateral lumbar spine radiography.

The presence of AAC in a plain radiography has been reported to be associated with an increased risk of $\mathrm{CV}$ events, CV mortality [13], and congestive heart failure [30] in the Framingham cohort. Overall, AAC adds to the prediction for intermittent claudication (IC), ischemic stroke (IS), and coronary heart disease over and above traditional CV risk factors in patients with low and intermediate risk [16]. AAC deposits also demonstrated to be a predictor of incident stroke in the Rotterdam study, even stronger than carotid plaques [31]. Both the Rotterdam and the Framingham studies used a quantitative scale to grade the severity of the aortic calcium deposits. It is worth noting that, even though the increase of $\mathrm{CV}$ risk was found to be proportional to the extent of the calcifications, AAC demonstrated to be a predictor of $\mathrm{CV}$ events and mortality also in cases of reduced calcifications. In keeping with these findings, in a Netherlands population Witteman et al. [32] found a strong independent association between $\mathrm{CV}$ deaths and aortic calcifications of any size, regardless of the extent of the calcific deposits. A postmortem study that analyzed the accuracy of the radiologic AAC for the diagnosis of true aortic atherosclerosis confirmed that even the smaller densities indicated the presence of advanced atheromatous plaques, which were almost invariably ulcerated [14]. Witteman et al. [32] also disclosed a high predictive role of AAC for $\mathrm{CV}$ death in young individuals, with a six-fold increased risk in men aged 45 years independently of the major CV risk factors, and no excess risk at age 75 years. These findings are particularly relevant in AS patients since the disease typically starts before the age of 45 years and the TC-SCORE tends to underestimate the $\mathrm{CV}$ risk, especially in this age group in which practically all patients are classified as having low or moderate $\mathrm{CV}$ risk. Indeed, the mean age in our series was 48 years and 118 of the 125 (94\%) AS patients were found to have a low or moderate TC-SCORE.

The 2014 ESC guidelines on the diagnosis and treatment of aortic diseases [33] recommended adopting general preventive measures to control risk factors in the presence of aortic atherosclerosis. Treatment with statins led to regression of thoracic aortic and retardation of abdominal aortic atheroma burden assessed by magnetic resonance imaging [34], as well as reduction of the inflammation assessed by PET [35]. In a retrospective study of 519 patients with severe aortic plaque seen on transesophageal echocardiography, only statin treatment was associated with a 70\% lower risk of events [36]. A correlation between AAC and atherosclerotic findings in the carotid and coronary arterial beds has previously been reported $[15,37]$. This finding constitutes an additional argument to support statin use in AS patients with AAC. The presence of carotid plaques, considered a surrogate marker of subclinical atherosclerosis in the 2016 ESC guidelines, automatically implies a very high $\mathrm{CV}$ risk with the consequent indication of statin use. Taking into account these considerations, we can conclude that almost $50 \%$ of AS included in the categories of low and moderate $\mathrm{CV}$ risk according to the TCSCORE risk algorithm would benefit from additional primary prevention measures, with special emphasis on the use of statins, if a plain lateral lumbar spine radiography is performed. This is a crucial aspect considering that statins have been shown to decrease mortality by $37 \%$ in AS, a figure double that observed in the general population [8].

The major limitation of our study was the absence of prospective follow-up data for the studied patients. Because of this, we dealt with a surrogate outcome based on extrapolation of the data that might not be applicable to AS.

In an attempt to elucidate the best strategy to identify AS patients at high CV risk, we assessed the ability of lateral lumbar spine radiography to detect severe findings of subclinical atherosclerosis. A predictive model 
that included a TC-SCORE $\geq 5 \%$ or the presence of AAC in lateral lumbar spine radiography in patients with a low or moderate TC-SCORE (TC-SCORE $<5 \%$ ) allowed us to detect half of the AS patients with high/very high CV-risk, also demonstrating a high degree of specificity (95.7\%).

\section{Conclusions}

When carotid US is not available, plain lateral lumbar spine radiography can be an easy and affordable tool to identify AS patients at high CV risk.

\section{Abbreviations}

AAC: Abdominal aortic calcium; AS: Ankylosing spondylitis;

ASDAS: Ankylosing Spondylitis Disease Activity Score; BASDAI: Bath Ankylosing Spondylitis Disease Activity Index; BASFI: Bath Ankylosing Spondylitis Functional Index; BASMI: Bath Ankylosing Spondylitis Metrology Index; CRP: C-reactive protein; CV: Cardiovascular; ESR: Erythrocyte sedimentation rate; FRS: Framingham Risk Score; IC: Intermittent claudication; IQR: Interquartile range; IS: Ischemic stroke; MASES: Maastricht Ankylosing Spondylitis Enthesitis Score; MDCT: Multidetector coronary tomography; OR: Odds ratio; ROC: Receiver operating characteristic; SD: Standard deviation; TC-SCORE: Total cholesterol systematic coronary risk evaluation; TNF: Tumor necrosis factor; US: Ultrasonography

\section{Availability of data and materials}

The datasets generated and/or analyzed during the current study are not publicly available because the individual privacy could be compromised, but are available from the corresponding author on reasonable request.

\section{Authors' contributions \\ JR-G made substantial contributions to the conception and design of the manuscript. FG analyzed and interpreted the patient data. AC and RB were involved in acquisition and analysis of data. PF, VP, RE, and CM were involved in acquisition and interpretation of data. TP was involved in acquisition and analysis of data. CG-J revised the manuscript critically for im- portant intellectual content. LR-R analyzed and interpreted the patient data. MAG-G was involved in the conception and drafting and revising the manu- script critically for important intellectual content. All authors read and ap- proved the final manuscript.}

\section{Ethics approval and consent to participate}

The subject's written consent was obtained in all cases. The study was approved by the local ethical committee.

\section{Consent for publication}

Not applicable.

\section{Competing interests}

The authors declare that they have no competing interests.

\section{Publisher's Note}

Springer Nature remains neutral with regard to jurisdictional claims in published maps and institutional affiliations.

\footnotetext{
Author details

${ }^{1}$ Epidemiology, Genetics and Atherosclerosis Research Group on Systemic Inflammatory Diseases, Division of Rheumatology, Hospital Universitario Marqués de Valdecilla, IDIVAL, University of Cantabria, Avenida de Valdecilla, s/n, 39008 Santander, Spain. ²Division of Rheumatology, Hospital Comarcal, Laredo, Cantabria, Spain. ${ }^{3}$ Division of Cardiology, Hospital Lucus Augusti, Lugo, Spain. ${ }^{4}$ Division of Rheumatology, Instituto de Investigación Sanitaria del Hospital Clínico San Carlos (IDISSC), Hospital Clínico San Carlos, Madrid, Spain. ${ }^{5}$ Cardiovascular Pathophysiology and Genomics Research Unit, School of Physiology, Faculty of Health Sciences, University of the Witwatersrand, Johannesburg, South Africa.
}

Received: 5 March 2018 Accepted: 23 July 2018

Published online: 29 August 2018

\section{References}

1. Peters MJ, van der Horst-Bruinsma IE, Dijkmans BA, Nurmohamed MT. Cardiovascular risk profile of patients with spondylarthropathies, particularly ankylosing spondylitis and psoriatic arthritis. Semin Arthritis Rheum. 2004;34 585-92.

2. Rueda-Gotor J, Corrales A, Blanco R, Fuentevilla P, Portilla V, Expósito R, et al. Atherosclerotic disease in axial spondyloarthritis: increased frequency of carotid plaques. Clin Exp Rheumatol. 2015;33:315-20.

3. Gonzalez-Juanatey C, Vazquez-Rodriguez TR, Miranda-Filloy JA, Dierssen T, Vaqueiro I, Blanco R, et al. The high prevalence of subclinical atherosclerosis in patients with ankylosing spondylitis without clinically evident cardiovascular disease. Medicine (Baltimore). 2009:88:358-65.

4. Mathieu S, Pereira B, Soubrier M. Cardiovascular events in ankylosing spondylitis: an updated meta-analysis. Semin Arthritis Rheum. 2015;44:551-5.

5. Haroon NN, Paterson JM, Li P, Inman RD, Haroon N. Patients with ankylosing spondylitis have increased cardiovascular and cerebrovascular mortality: a population-based study. Ann Intern Med. 2015;163(6):409-16.

6. Piepoli MF, Hoes AW, Agewall S, Albus C, Brotons C, Catapano AL, et al. 2016 European Guidelines on cardiovascular disease prevention in clinical practice: The Sixth Joint Task Force of the European Society of Cardiology and Other Societies on Cardiovascular Disease Prevention in Clinical Practice (constituted by representatives of 10 societies and by invited experts) Developed with the special contribution of the European Association for Cardiovascular Prevention \& Rehabilitation (EACPR). Eur Heart J. 2016;37: 2315-81.

7. Taylor F, Huffman MD, Macedo AF, Moore TH, Burke M, Davey Smith G, et al. Statins for the primary prevention of cardiovascular disease. Cochrane Database Syst Rev. 2013;1:CD004816.

8. Oza A, Lu N, Sr S, Fisher MC, Dubreuil M, Rai SK, et al. Survival benefit of statin use in ankylosing spondylitis: a general population-based cohort study. Ann Rheum Dis. 2017;76(10):1737-42

9. Wright KA, Crowson CS, Michet CJ, Matteson EL. Time trends in incidence, clinical features, and cardiovascular disease in ankylosing spondylitis over three decades: a population-based study. Arthritis Care Res (Hoboken). 2015 67:836-41.

10. Nambi V, Chambless L, Folsom AR, He M, Hu Y, Mosley T, et al. Carotid intima-media thickness and presence or absence of plaque improves prediction of coronary heart disease risk: the ARIC (Atherosclerosis Risk in Communities) study. J Am Coll. 2010;55:1600-7.

11. Detrano R, Guerci AD, Carr JJ, Bild DE, Burke G, Folsom AR, et al. Coronary calcium as a predictor of coronary events in four racial or ethnic groups. $\mathrm{N}$ Engl J Med. 2008;358(13):1336-45.

12. Rueda-Gotor J, Llorca J, Corrales A, Parra JA, Portilla V, Genre F, et al. Cardiovascular risk stratification in axial spondyloarthritis: carotid ultrasound is more sensitive than coronary artery calcification score to detect highcardiovascular risk axial spondyloarthritis patients. Clin Exp Rheumatol. 2018; 36(1):73-80.

13. Wilson PW, Kauppila LI, O'Donnell CJ, Kiel DP, Hannan M, Polak JM, et al. Abdominal aortic calcific deposits are an important predictor of vascula morbidity and mortality. Circulation. 2001;103(11):1529-34

14. Hyman JB, Pstein FN. A study of the correlation between roentgenographic and post-mortem calcification of the aorta. Am Heart J. 1954;48(4):540-3.

15. Eggen DA, Strong JP, Mcgill HC Jr. Calcification in the abdominal aorta; relationship to race, sex, and coronary atherosclerosis. Arch Pathol. 1964;78: 575-83

16. Levitzky YS, Cupples LA, Murabito JM. Prediction of intermittent claudication, ischemic stroke, and other cardiovascular disease by detection of abdominal aortic calcific deposits by plain lumbar radiographs. Am J Cardiol. 2008;101(3):326-31

17. van der Linden S, Valkenburg HA, Cats A. Evaluation of diagnostic criteria for ankylosing spondylitis. A proposal for modification of the New York criteria. Arthritis. Rheum. 1984;27:361-8.

18. Garrett S, Jenkinson T, Kennedy LG, Whitelock H, Gaisford P, Calin A. A new approach to defining disease status in ankylosing spondylitis: the bath Ankylosing Spondylitis Disease Activity Index. J Rheumatol. 1994;21:2286-91.

19. Lukas C, Landewé R, Sieper J, Dougados M, Davis J, Braun J, et al. Development of an ASAS-endorsed disease activity score (ASDAS) in patients with ankylosing spondylitis. Ann Rheum Dis. 2009;68:18-24. 
20. Calin A, Garrett S, Whitelock H, Kennedy LG, O'Hea J, Mallorie P, et al. A new approach to defining functional ability in ankylosing spondylitis: the development of the Bath Ankylosing Spondylitis Functional Index. J Rheumatol. 1994;21:2281-5.

21. Jenkinson TR, Mallorie PA, Whitelock HC, Kennedy LG, Garrett SL, Calin A. Defining spinal mobility in ankylosing spondylitis (AS). The Bath AS Metrology Index. J Rheumatol. 1994;21:1694-8.

22. Heuft-Dorenbosch L, Spoorenberg A, Van Tubergen A, et al. Assessment of enthesitis in ankylosing spondylitis. Ann Rheum Dis. 2003;62:127-32.

23. Goff DC Jr, Lloyd-Jones DM, Bennett G, Coady S, D'Agostino RB Sr, Gibbons $\mathrm{R}$, et al. 2013 ACC/AHA guideline on the assessment of cardiovascular risk: a report of the American College of Cardiology/American Heart Association task force on practice guidelines. J Am Coll Cardiol. 2014;63:2935-59.

24. D'Agostino RB, Vasan RS, Pencina MJ, Wolf PA, Cobain M, Massaro JM, et al. General cardiovascular risk profile for use in primary care: the Framingham Heart Study. Circulation. 2008;117:743-53.

25. Ridker PM, Buring JE, Rifai N, Cook NR. Development and validation of improved algorithms for the assessment of global cardiovascular risk in women: the Reynolds Risk Score. JAMA. 2007;297:611-9.

26. Marrugat J, Subirana I, Comín E, Cabezas C, Vila J, Elosua R, et al. Validity of an adaptation of the Framingham cardiovascular risk function: the VERIFICA study. J Epidemiol Community Health. 2007;61:40-7.

27. Touboul PJ, Hennerici MG, Meairs S, Adams H, Amarenco P, Bornstein N, et al. Mannheim carotid intima-media thickness and plaque consensus (20042006-2011). An update on behalf of the advisory board of the 3rd, 4th and 5th watching the risk symposia, at the 13th, 15th and 20th European Stroke Conferences, Mannheim, Germany, 2004, Brussels, Belgium, 2006, and Hamburg, Germany, 2011. Cerebrovasc Dis. 2012;34:290-6.

28. Vihert AM. Atherosclerosis of the aorta in five towns. Bll WId HIth Org. 1976; 53:501-8.

29. Mitchell JRA, Adams JH. Aortic size and aortic calcification: a necropsy study. Atherosclerosis. 1977;27:437-46.

30. Walsh CR, Cupples LA, Levy D, Kiel DP, Hannan M, Wilson PW, et al. Abdominal aortic calcific deposits are associated with increased risk for congestive heart failure: the Framingham Heart Study. Am Heart J. 2002; 144(4):733-9.

31. Hollander M, Hak AE, Koudstaal PJ, Bots ML, Grobbee DE, Hofman A, et al. Comparison between measures of atherosclerosis and risk of stroke: the Rotterdam Study. Stroke. 2003;34(10):2367-72.

32. Witteman JC, Kok FJ, van Saase JL, Valkenburg HA. Aortic calcification as a predictor of cardiovascular mortality. Lancet. 1986;2(8516):1120-2.

33. Erbel R, Aboyans V, Boileau C, Bossone E, Bartolomeo RD, Eggebrecht H, et al. 2014 ESC guidelines on the diagnosis and treatment of aortic diseases: document covering acute and chronic aortic diseases of the thoracic and abdominal aorta of the adult. The task force for the diagnosis and treatment of aortic diseases of the European Society of Cardiology (ESC). Eur Heart J. 2014;35(41):2873-926.

34. Yonemura A, Momiyama Y, Fayad ZA, Ayaori M, Ohmori R, Kihara T, et al. Effect of lipid-lowering therapy with atorvastatin on atherosclerotic aortic plaques: a 2-year follow-up by noninvasive MRI. Eur J Cardiovasc Prev Rehabil. 2009;16(2):222-8.

35. Tahara N, Kai H, Ishibashi M, Nakaura H, Kaida H, Baba K, Hayabuchi N, Imaizumi T. Simvastatin attenuates plaque inflammation: evaluation by fluorodeoxyglucose positron emission tomography. J Am Coll Cardiol. 2006; 48:1825-31.

36. Tunick PA, Nayar AC, Goodkin GM, Mirchandani S, Francescone S, Rosenzweig BP, Freedberg RS, Katz ES, Applebaum RM, Kronzon I. Effect of treatment on the incidence of stroke and other emboli in 519 patients with severe thoracic aortic plaque. Am J Cardiol. 2002;90:1320-5.

37. Lewis JR, Schousboe JT, Lim WH, Wong G, Zhu K, Lim EM, et al. Abdominal aortic calcification identified on abdominal aortic calcification identified on lateral spine images from bone densitometers are a marker of generalized atherosclerosis in elderly women. Arterioscler Thromb Vasc Biol. 2016;36(1): $166-73$.

\section{Ready to submit your research? Choose BMC and benefit from:}

- fast, convenient online submission

- thorough peer review by experienced researchers in your field

- rapid publication on acceptance

- support for research data, including large and complex data types

- gold Open Access which fosters wider collaboration and increased citations

- maximum visibility for your research: over $100 \mathrm{M}$ website views per year

At BMC, research is always in progress.

Learn more biomedcentral.com/submissions 